\title{
Abstract and Preface
}

Verbatim theatre, a type of performance based on actual words spoken by "real people," has been at the heart of a remarkable and unexpected renaissance of the genre in the United Kingdom since the mid-nineties. Simultaneously, contemporary British theatre-makers claimed to have found a renewed avenue to politics through this particular medium. In spite of recent shifts in the British theatrical landscape as well as the much-vaunted postmodern culture of anti-realism, documentary realism is generally conceded to have remained the normative mode of presentation for verbatim plays on stage. Through a comparative examination of seven representative verbatim productions, this book argues, however, that there has been an equally persistent strand of verbatim works that involves a move away from realism as the key element in performance. These productions make use of a wide variety of aesthetic experiments that broaden and transgress what we might understand as verbatim theatre. The strategy adopted by this study is thus to read verbatim theatre against the grain of its claim to "authenticity" and "truthfulness" and to suggest the need for a discourse which better articulates an interdependence between its aesthetic imperatives and the possibilities of social engagement. Finally, this volume accounts for the existence of a range of aesthetic variables in present-day verbatim theatre which is aimed at more media-aware contemporary audiences. These are grouped into three theoretical positions, each of them being analysed and discussed in a separate part and illustrated by case studies. It is hoped that, through this argument, the changing aesthetics of verbatim theatre will be illuminated and that - on however small a scale - this book will contribute to a critical history and theoretical formulation of the complexity of this rich field as both a scholarly discipline and a lived practice.

In broad terms, the central aim of the book is therefore to critically explore and account for the relationship between contemporary British verbatim theatre and realism whilst questioning the problematic mediation of the real in these theatre practices. Taken together, the seven case studies in this volume - the Tricycle Theatre's Justifying War (2003), Robin Soans' A State Affair (2000), David Hare's Stuff Happens (2004), Alecky Blythe's Come Out Eli (2003), DV8's To Be Straight with You (2008), Alecky Blythe and Adam Cork's London Road (2011), and Jonathan Holmes' Fallujah (2007) - challenge effectively the widespread assumption that verbatim theatre is formally homogenous, aesthetically unadven- 
turous, and/or in decline. ${ }^{1}$ In other words, this study, which showcases a wide variety of aesthetic transgressions from the "original" verbatim orthodoxy, questions the frequent assumption that verbatim theatre represents the degree zero of the aesthetic, by showing that even the most seemingly straightforward realist forms, such as tribunal plays, rely, nevertheless, on specific aesthetic practice and process. It is not only that verbatim theatre is interested in stirring up controversy, but that the means it uses to achieve this are highly counterintuitive, as the following pages will demonstrate through a reconsideration of both verbatim theatre's moral imperative and its political efficacy. More specifically and through a tripartite theoretical structure, I set in place a taxonomy of verbatim dramaturgies - documentary realism (Chapter 2), new realism (Chapter 3), and post-realism (Chapter 4) - that reinforces, reflexively interrogates, and/or deconstructs theatre's arbitration and excavation of the documentary real.

1 In April 2018, the Tricycle Theatre was renamed Kiln Theatre. However, as the case studies in this book do not cover this period, the name Tricycle Theatre is kept throughout. 